\title{
Effect of Aqueous and Alcoholic Extract of Eucalyptus Camaldulensis Dehn Leaves on Growth of Fungal Root Rot of Pinus Brutia Ten In Vitro
}

\author{
Anwer Noori Mohammed Al-Khero ${ }^{*}$; Muhannad Hamid Younis Al-Obaidy ${ }^{2}$ \\ Forestry Department, college of Agriculture and Forestry Mosul University, Mosul, Iraq \\ Email: ${ }^{1}$ mmuhannad233@gmail.com, ${ }^{2}$ anweral-khero@yahoo.com
}

(Received December 12, 2018; Accepted May 16, 2019; Available online March 01, 2020)

DOI: 10.33899/edusj.2020.164364, (C) 2020, College of Education for Pure Science, University of Mosul.

This is an open access article under the CC BY 4.0 license (http://creativecommons.org/licenses/by/4.0/).

\begin{abstract}
:
Root Rot disease is one of important disease which caused great damage for Pinus brutia and was very clear the field Survey of Mosul nurseries, 3 nurseris in AL-Faisalih location, 3 nurseris in Muthanna, 1 nurseris in AL-Mohandiseen location and Nineveh Horticulture station, this was through October and December of 2017 and February , April , June and August of 2018.fungi were recorded like Fusarium solani Mart Insulalation ratia 27.80\% ,Macrophomina phaseolina Tassi Goid Insulalation ratia $18.76 \%$ and Rhzoctonia solani Khun Insulalation ratia $16.48 \%$ which Isolated from Pinus brutia Seedling .Pathogenicity tests Results showed Fusarium poae was had high pathogenicity $87.5 \%$ Pinus brutia seedling and the fungus was very effective at growth characteristics.

The study of Eucalyptus camaldulnsis leaves Extracts effect at the growth of Isolated fungi growth inhibition and for all studying concentration as a compartment with aqueous extracted especially leaves Alcoholic extracts Rhizoctonia solani was morally effect by aqueous leaves extracted.
\end{abstract}

Keywords: Pinus, root rot, Fungi, Extracts, Eucalyptus.

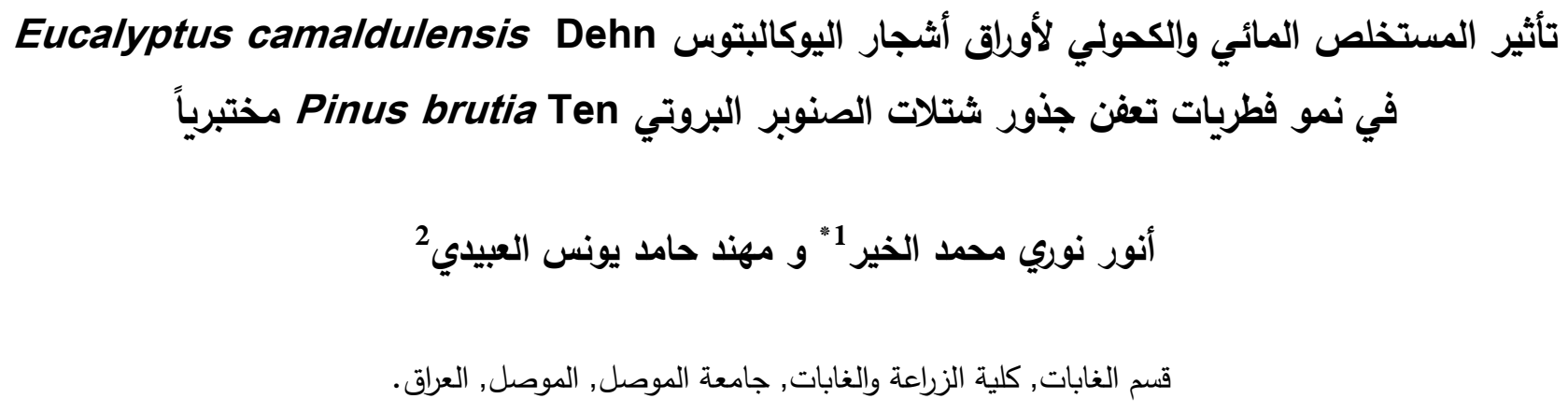

الخلاصة

يعد مرض تعفن الجذور من الامراض التي تسبب أضراراً بالغة لشتلات الصنوبر البروتي Pinus brutia وقد ظهر ذلك جلياً في مشاتل الغابات الخاصة في الموصل وذلك لثلاث مشاتل في منطقة الفيصلية وثلاث مشاتل في منطقة المثنى ومشتل في منطقة المهندسين فضلاً عن محطة بستنة نينوى خلال المسح الحقلي الذي أجري في تلك المشاتل وخلال شهر تشرين الاول وشهر كانون 
الاول في عام 2017 والاشهر شباط ونيسان وحزيران وأب في عام2018 وتم تسجيل الفطريات Fusarium solani Mart بنسبة

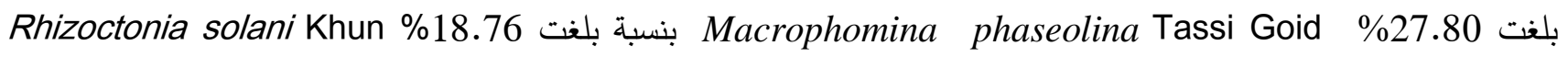
بنسبة بلغت 16.48\% كمسببات لتعفن جذور شتلات الصنوبر البروتي Pinus brutia ـوأظهرت نتائج القدرة الإمراضية للفطريات المعزولة تفوق الفطر Fusarium solani بأعلى نسبة إصابة بلغت 81.25\% لشتلات الصنوبر البروتي كذلك أحدث الفطر تأثيراً معنوياً بالغاً في جميع صفات النمو مقارنةً بالفطريات الاخرى, وفي دراسة تأثير مستخلصات أوراق أشجار اليوكالبتوس Euycalyptus camaldulensis Dehn الفطريات المعزولة مقارنة بالمستخلص المائي ولجميع التراكيز باستثناء الفطر Rhizoctonia solani الذي أنغرد في تتبيطه معنوياً

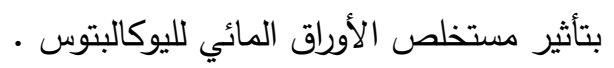

الكلمات المفتاحية: الصنوبر ، تعفن الجذور ، الفطريات، مستخلصات، اليوكالبتوس.

\section{المقدمة Introduction}

تعد الغابات من أهم النظم البيئية المتطورة وأعقدها وأكثرها ارتباطاً بحياة الإنسان، لما تمتلكه من مدًخرات وراثية هائلة(1). وما تقدمه من منتجات اقتصادية : كالخشب، والمواد العطرية، والطبية، والعلفية، والمواد الغذائية، إلى جانب فوائدها في السياحة والاستجمام ،.... وما تملكه من فوائد بيئية (2). تغطي الغابات 30\% تقريباً من سطح الأرض، وتعد مخزناً لحوالي

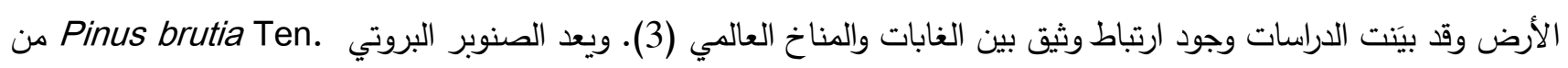

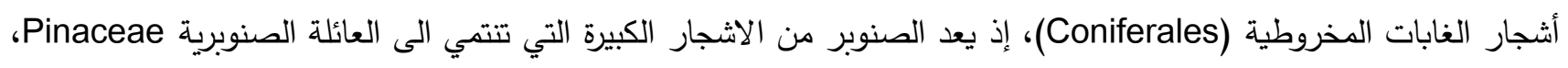

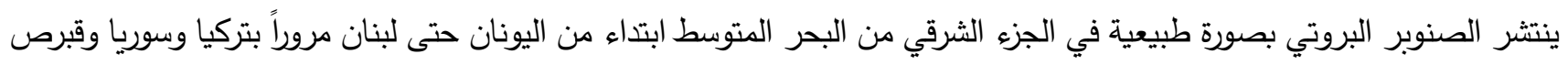

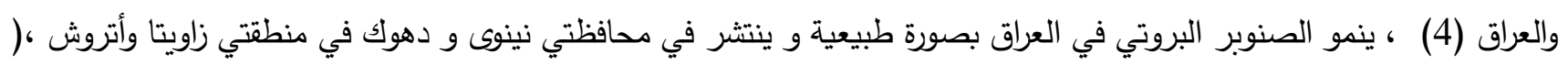

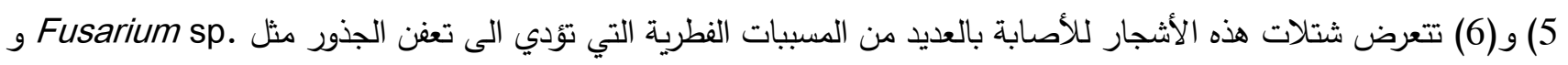
M. phaseolina R. solani و Microdochium bolleyi و M. phaseolina و Fusarium sp g. oxysporum gylindrocarpon tenue. Rhizoctonia sp. Pythium sp. و Phoma pomorum, Pestiolopsis funera و و و 9 9 و). ونتيجة لازدياد خطورة أمراض النبات من جهة وسلبيات المبيدات الكيميائية من جهة أخرى، فقد أكدت عدة دراسات نجاح استعمال المستخلصات

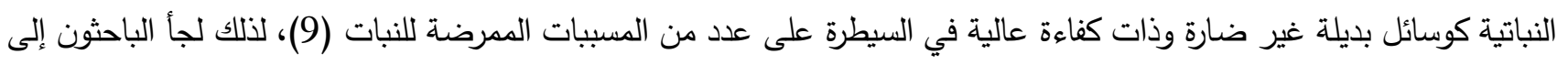

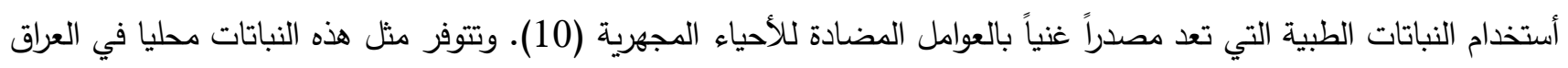
كأشجار اليوكالبتوس ونباتات الأس والحرمل والثوم والتي يمكن اعتماد اجزائها كمستخلصات نباتية في المكافحة تجنباً لاستخدام

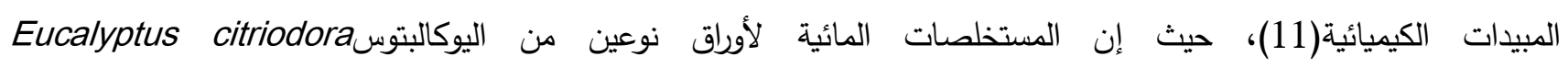

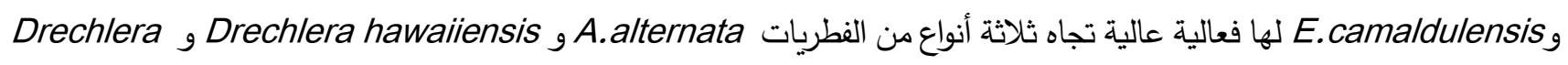
tetramera والوزن الجاف للفطريات A. Altemata و Alocladium qtrum و (13). تفوق تأثير المستخلصات الكحولية لأوراق اليوكالبتوس Eucalyptus camadulensis والنعناع الفلفلي Menthapiperta والكزبرة Coridndru sativum على تأثير

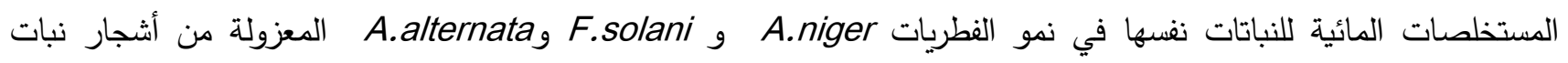
الدردار(14). ويعدُ . Eucalyptus camaldulensis Dehn من الأشجار السريعة النمو والأنواع التي نجحت في الغابات الاصطناعية ويستخدم للأغراض الطبية والعلاجية (5 و 15 (15) وان اوراق Eucalyptus camaldulensis تحتوي على triterpeoids 
و fterol و و flavonoinnins و والمركبات الفينولية ـ (16).حيث هدفت هذه الدراسة الى المسح الحقلي لمرض تعفن الجذور وعزل الفطريات المصاحبة لمرض تعفن جذور شتلات الصنوبر البروتي وأختبار القدرة الأمراضية للفطريات المعزولة

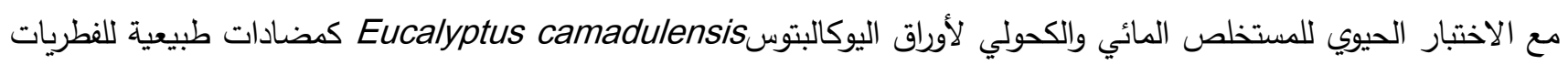
المعزولة مختبرياً.

\section{Materials and methods المواد وطرائق العمل}

\section{المسح الحقلي لمسببات تعفن الجذور}

تم اجراء مسـح حقلي لمشـاتل خاصــة في الموصـل ثلاثة بمنطقة الفيصـلية وثلاثة في منطقة المثنى ومشـتل في منطقة المهندسين اضافة الى محطة بستتة نينوى لمرض تعفن جذور صنوبر بروتيا P. brutia لشتلات بأعمار تتراوح ما بين (1-3) سنوات خلال

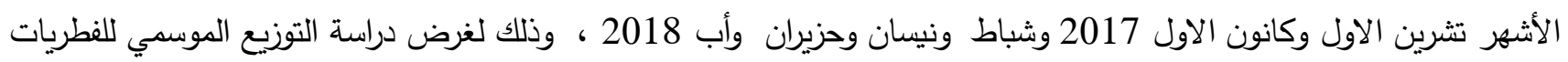

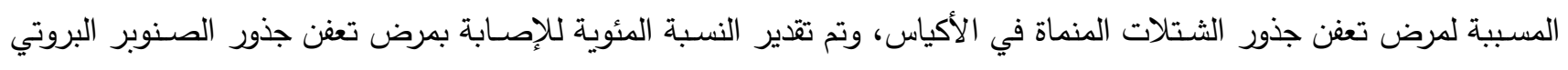

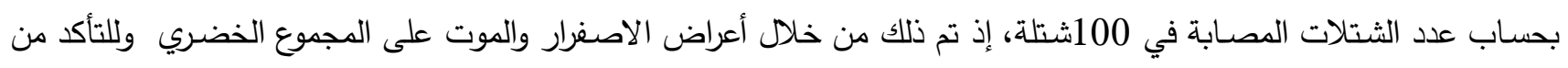
أصــابتها اخذت عينات عشــوائية وفحص المجموع الجذري من خلالها وتم ملاحظة أعراض التعفن في بشــرة الجذور والثــعيرات الجذرية.

$$
\begin{aligned}
& \text { استخرجت النسبة المئوية للإصابة على النحو التالي :- }
\end{aligned}
$$

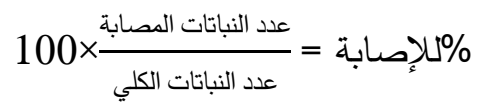

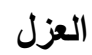

جلبت عينات من الثـتلات المصـابة من الصنوبر بروتي Prutia . خلال فترة المسـح في المشـاتل المدسوحة وأخذت اجزاء منها

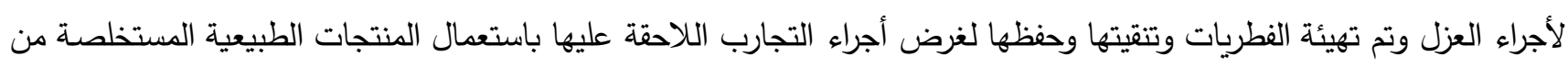
أوراق اشـــار اليوكالبتوس Eucalyptus camaldulensis حيث تم عزل هذه الفطريات من الثــتلات المصــــابة بتعفن الجذور

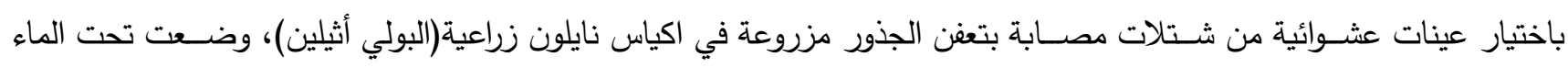

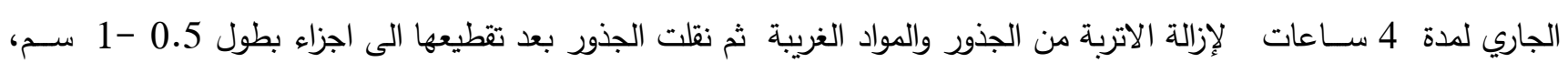

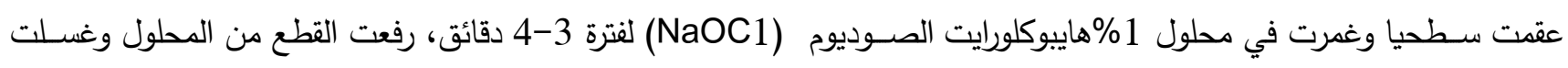
بماء مقطر معقم، وجفقت بين ورقتي ترشيح معقة وزرعت في اطباق بتري معقدة (قطر 8.5 سم) حاوية على الوسط المغذي اجار

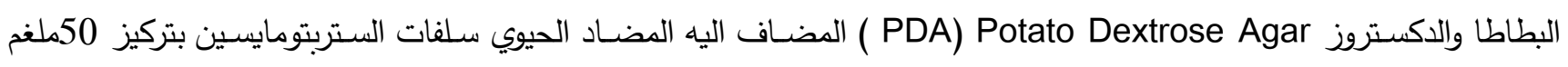
/لتر لكنع نمو البكتريا قبل تصــلبه. وبمعدل 4 قطع / طبق، حضـــنت الاطباق في درجة حرارة 25+- 2 سـليزية، وأخذت النتائج

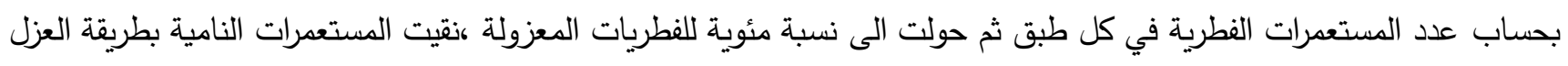

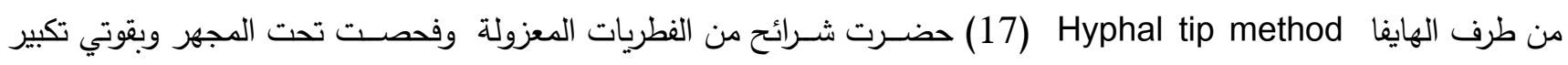

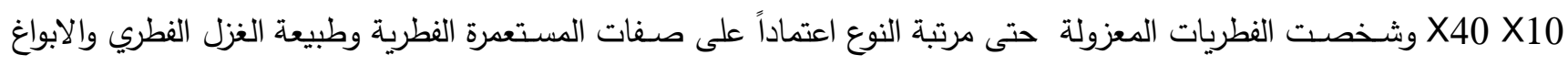

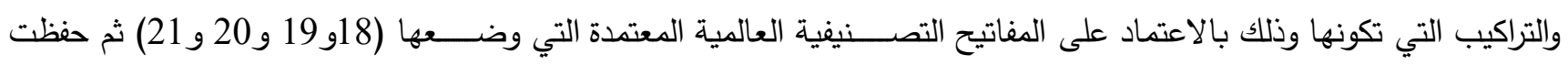
الفطريات المنتقاة في انابيب اختبار تحتوي على أكار مائل(slant) في 5 درجة سـليزية لغرض اســتـعمالها في الاختبارات اللاحقة وتم العزل بمعدل شهرين ولمدة سنة للنبات قيد الدراسة . وحسبت نسبة الفطريات المعزولة لكل نوع نباتي كالآتي:- 


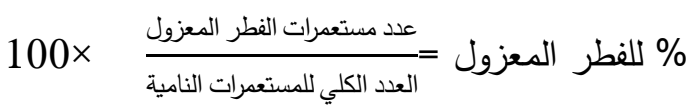

$$
\begin{aligned}
& \text { اختبار القدرة الامراضية للفطريات المعزولة }
\end{aligned}
$$

اجري اختبار القدرة الامراضية للفطريات F.solani و و M.phasolina و المسببة لتعفن الجذور بعد عزلها من الثتلات المصابة حسب طريقة(22) وذلك بعد تهيئة الثتلات السليمة بأعمار من (1-3) سنة المزروعة في أكياس زراعية حجم (3كغم) من

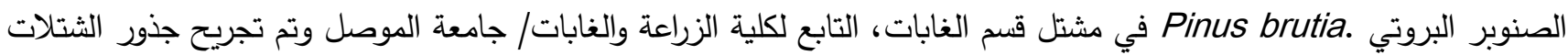
السليمة بواسطة مشرط حاد معقم بعد تهيئة الفطريات المستعملة في الاختبار والتي تم تنميتها على اوساط مغذية معقدة من اجار

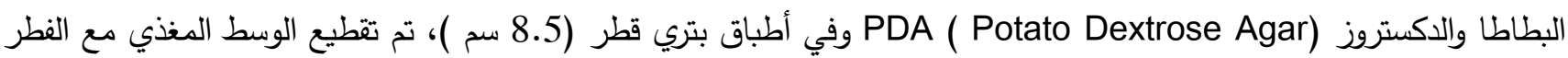
النامي بوساطة خلاطة كهربائية نوع Go sonic ، حيث أضيف طبقان لكل شتلة سليمة وتم خلطها مع تربة الجذور المجروحة

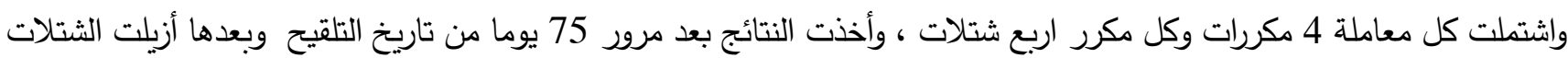
من التربة بواسطة الماء الجاري وتم حساب النسبة المئوية للإصابة لكل فطر على حدى لشتلات الصنوبر حسب العلاقة على النحو

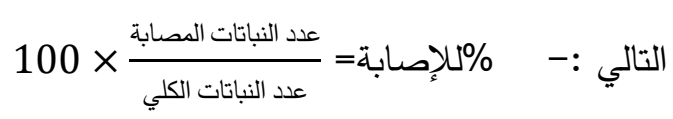

ولمعرفة تأثير هذه الفطريات الممرضــة على بعض صــفات النمو للثـتلات تم حسـاب طول المجموع الخضــري وطول المجموع

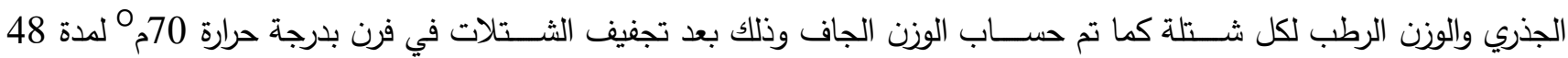

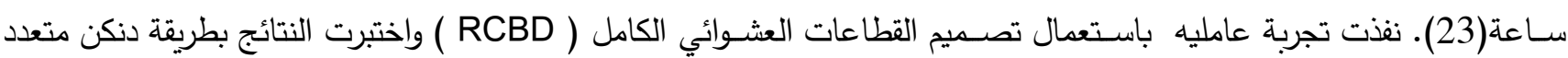

\section{تهيئة المواد الاولية وجمع العينات}

تم جمع عينات من أوراق اشجار اليوكالبتوس كمالدولينسيس Eucalyptus camaldulensis Dehn إذ جمعت الثينه الأوراق الناضجة

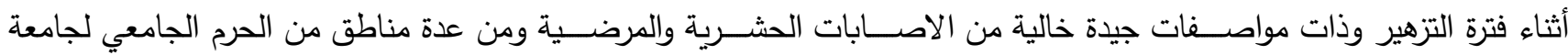

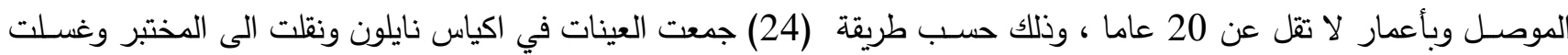

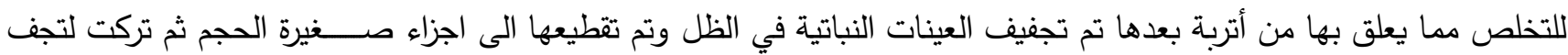

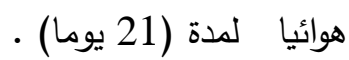

طحنت العينات النباتية باستعمال مطحنة كهربائية نوع (محلية الصنع) للاجزاء الصغيرة الجافة من والاوراق وجمعت الدقائق الصغيرة التي استقرت على منخل ( 60 مش ) بعد مرورها من خلال منخل ( 16 مش ) فأصبحت العينات جاهزة للاستخلاص (25). أ-تحضير المستخلص الكحولي للأوراق.

تم اعتماد طريقة(26) في استخلاص بعض المنتجات الطبيعية وذلك تبعا لنوع المذيب المستعمل وهو الايثانول 95\% .اجريت عملية

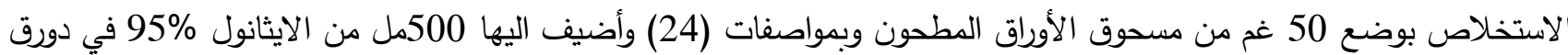
زجاجي سعة 500مل ،رجت العينة بواسطة جهاز الرج المغناطيسي (Magnetic sterier) ولدئ ولمدة 48 ساعة رُشح المزيج باستعمال عدة طبقات من الثاش الطبي ثم رشح المحلول من خلال ورق ترشيح Whatma No.1 ثم نقل المتبقي الى مرحلة الاستخلاص بالماء الحار، ركز مستخلص الاوراق في جهاز المبخر الدوار ( Rotary vaccum evaporator ) بدرجة حرارة 40 - 50م

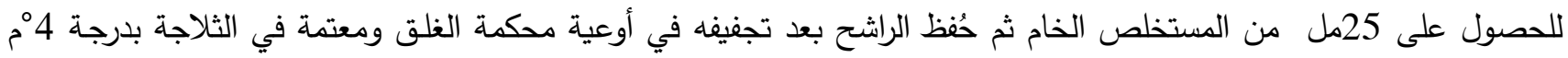
لحين الاستعمال وأجراء الاختبارات الحيوية (27). 
ب-تحضير المستخلص المائي الحار للأورلق. تم رفع ما تبقى من العينة التي سبق استخلاصـها باستعمال الإيثانول 95\% لتحضير مستخلص الاوراق الكحولي السـابق الذكر وجفقت العينة هوائيا ثم وضعت في في اناء زجاجي سعة لتر واحد وأضيف اليها 400مل من الماء الحار بدرجة حرارة 80 درجة سليزية وتم استعمال جهاز الرجاج الكهربائي Electric sterier للتحريك المستمر ولمدة 24ساعة ثم برد المحلول وتم تصفيته بواسطة قماش دراء

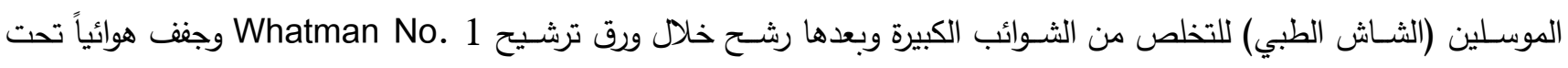
ظروف المختبر وتم الحصـول على مسـحوق من المسـتخلص المائي ثم حفظ المسـحوق في قناني معتمة محكمة الغلق لحين اجراء الاختبارات الحيوية.

الاختبارات الحيوية

تأثير المستخلص الكحولي والمائي في تثبيط النمو الفطري:-

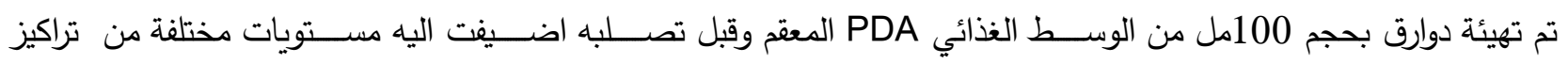

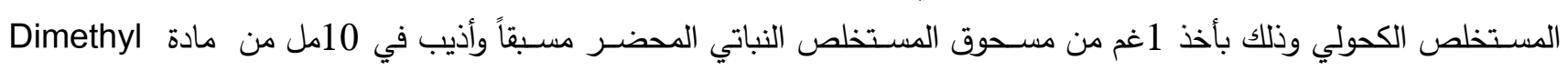
وبنفس الطريقة حضر المستخلص المائي وذلك بأضافة 1غم من المستخلص المائي 10مل ماء مقطر معقم وحضـرت التراكيز (25\% و 50\% و 75\% و 100\%) إضـافة الى معاملة المقارنة الخالية من المسـتخلص، ثم صـبت في اطباق

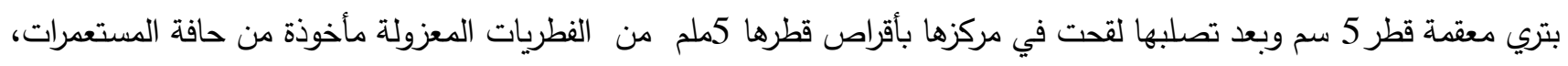
طرف الهايفا Hyphal tip method (17) واشــتملت المعاملة 4 مكررات وكل مكرر 3 أطباق بالاضـــافة الى معاملة المقارنة

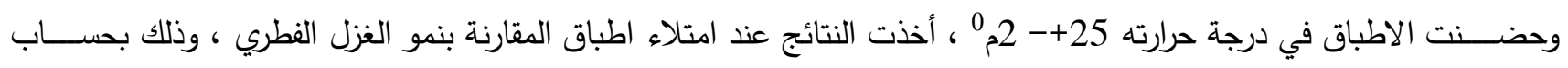
متوسط قياس قطرين متعامدين للمستعمرة النامية ومنه تم حساب نسبة تتبيط النمو حسب القانون الآتي : متوسط قياس قطر مستعمرة المقارنة - متوسط قياس قطر مستعمرة المعاملة $100 \times$ = لتبيط النمو متوسط قياس قطر مستعمرة المقارنة

نفذت تجربة عاملية وفق التصميم العشوائي الكامل (CRD) وحللت النتائج إحصائيا واختبرت بطريقة دنكن متعدد الحدود(28).

\section{Results and discussion النتائج والمناقشة} المسح الحقلي لمرض تعفن جذور شتلات الصنوبر البروتي. أظهرت نتأئج المسح الحقلي تباين في نسبة الإصابة بمرض تعفن جذور شتلات الصنوبر البروتي Prutia

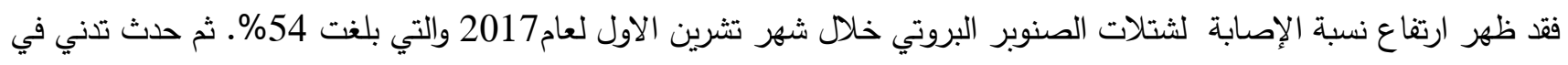

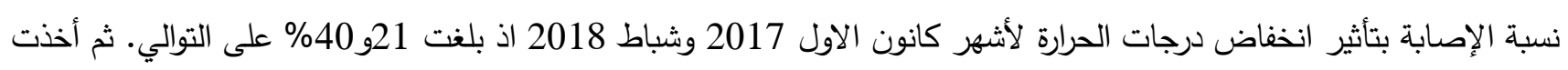

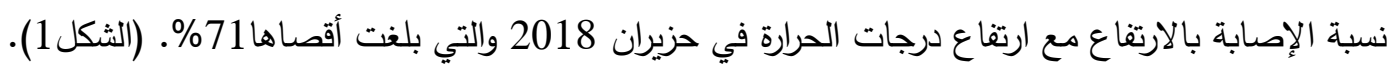




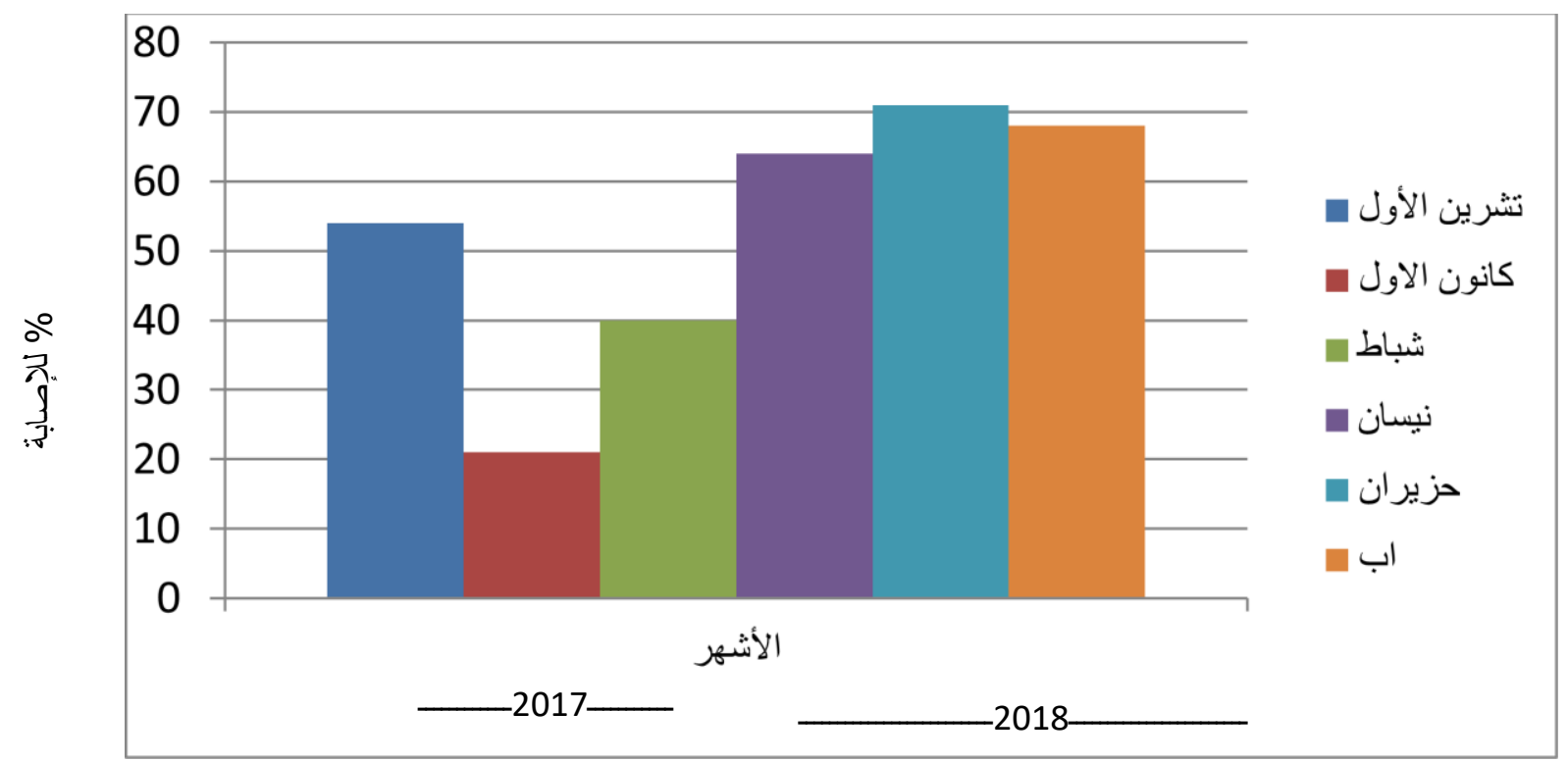

الثكل (1) \%للإصابة بتعفن جذور شتلات الصنوبر البروتي للأشهر من تشرين الاول 2017 الى أب 2018.

ان نسبة الإصابة المرتفعة بتعفنات الجذور كان منطقياً مع الادارة البدائية المتبعة لهذه المشاتل علما بأن المشاتل تتطلب برامج وقائية وعلاجية وتتظيمية من شأنها العمل على الحد من انتشار مسببات أمراض الجذور الخطرة(29). وتجدر الاشارة الى أن هذه المشاتل

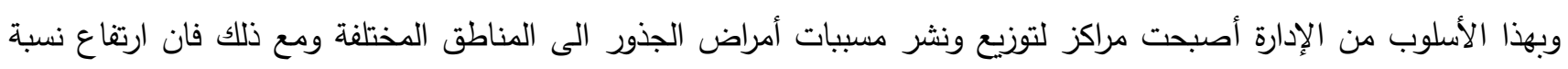

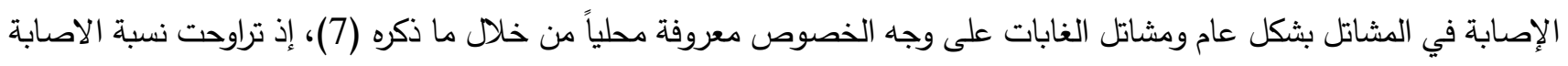
بمرض تعفن الجذور بين 5-100\% وفي مشاتل اخرى تراوحت بن 20-90\%(29) ليس في العراق فقط إنما يتعدى ذلك الى اكثر دول العالم إذ كانت هناك نسبة أصابة عالية كما في كثمير الهندية لمشاتل الصنوبر (30). اظهرت نتائج العزل لتعفن جذور شتلات الصنوبر البروتي Prutia في مشاتل الموصل الخاصة ومحطة بستتة نينوى خلال فترات المسح الحقلي أنفة الذكر وعلى النحو التالي:-

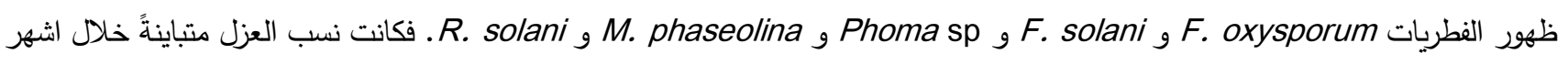

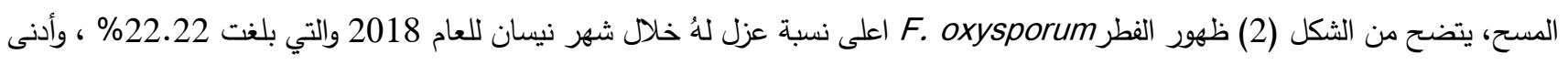

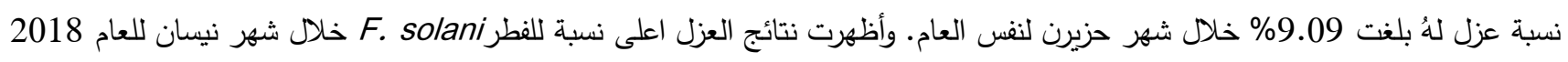

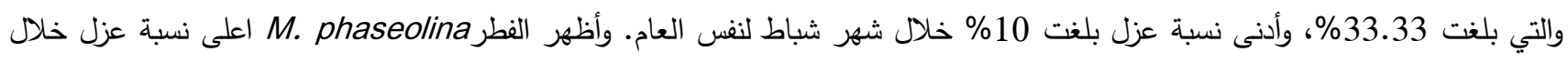

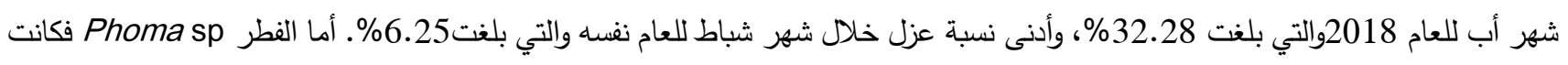

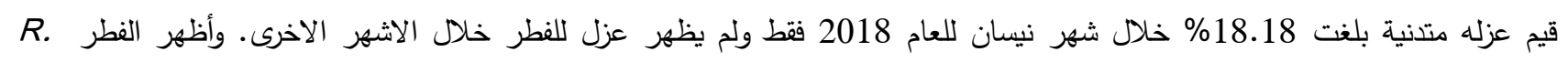
اعلى نسبة عزل بلغت 30.76olani 
Journal of Education and Science (ISSN 1812-125X), Vol: 29, No: 1, 2020 (75-92)

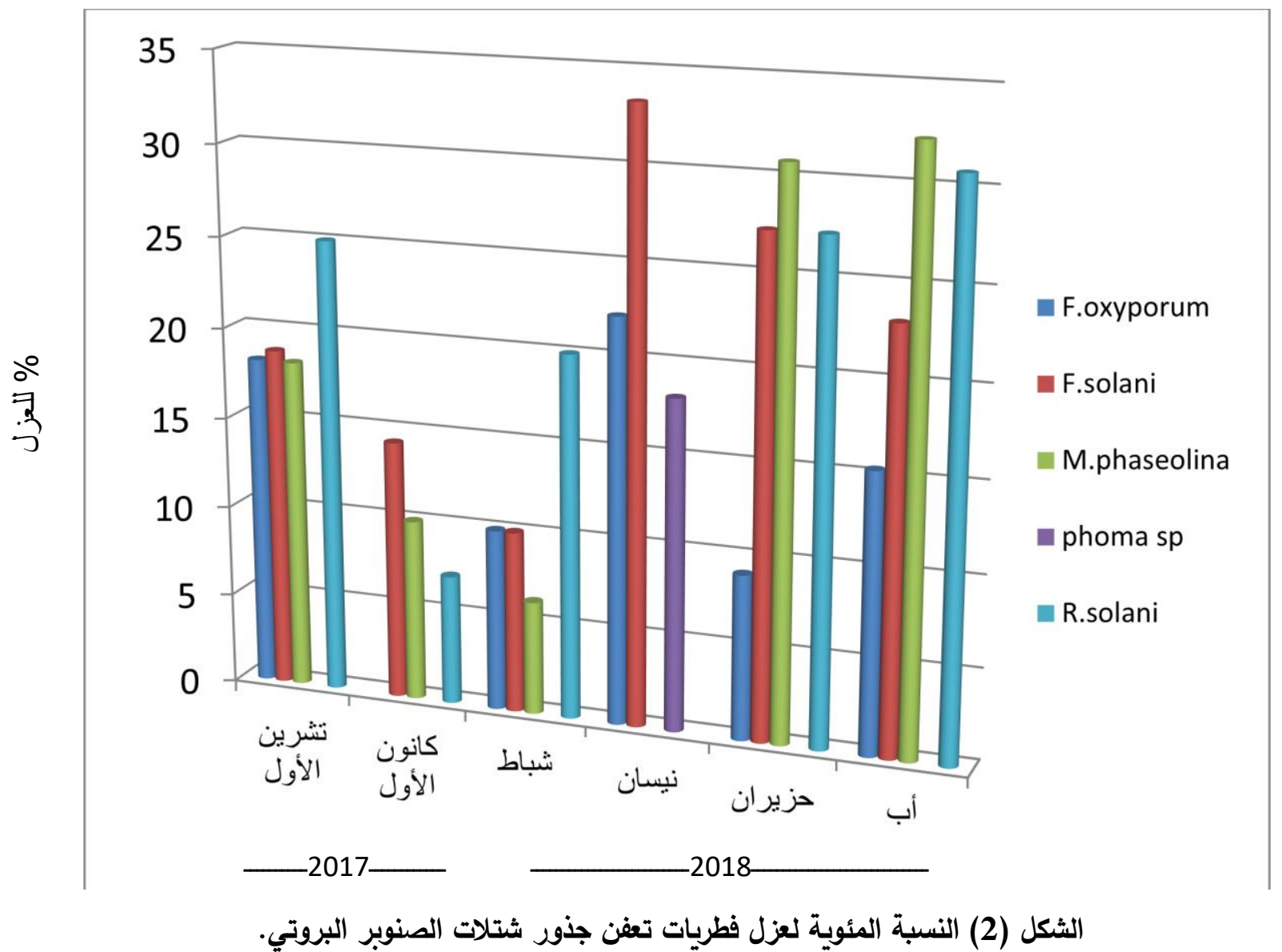

يتضح مما تقدم سيادة تامة للفطر F. solani على شتلات الصنوبر البروتي من خلال نسب تكرار وجود الفطر وربما يعود السبب لتطابق متطلباته الحرارية مع الظروف البيئية السائدة خلال أشهر المسح أضافةً الى أنه من اكثر فطريات التربة التربة انتشاراً واكثرها اهمية

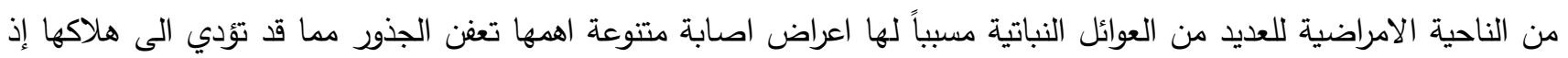
يعتبر فطر واسع الانتشار في التربة.(31) و(32).

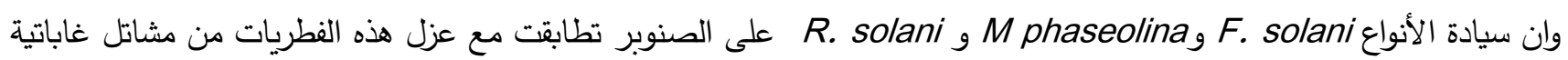

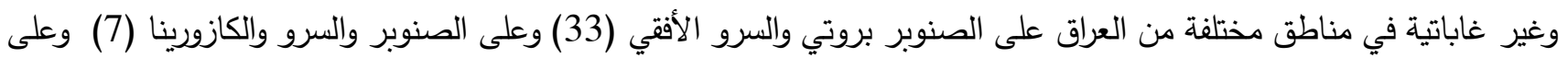
الثويا (34).

تشخيص ووصف الفطريات Fusarium solani Mart تشخيص الفطر أظهرت نتائج تثخيص الفطر F. solani على الوسط المغذي لمستخلص البطاطا الدكستروز والاكار PDA بعمر عشرة ايام في درجة حرارة 25 25 سليزية بظهور مستعمرات ذات لون ابيض إلى رمادي مع لون كريمي براق تشوبه صبغة بنفسجية في بعض الاحيان ، وأظهر الفحص المجهري بإن الفطر النامي يكون ثلاثة انواع من الابواغ الثكل(3)، الابواغ الكونيدية الصغيرة Microconidia مغزليه الثكل بلغت ابعادها 2.4-35.4×37-37 مايكروميتر والنوع الثالث هي الابواغ الكلاميدية 
مفردة أو بثكل أزواج في فروع جانبية صغيرة أو وسط الغزل الفطري وهذه الصفات تطابقت مع مفاتيح التصنيف المذكورة من قبل (20 و 21 و 35).

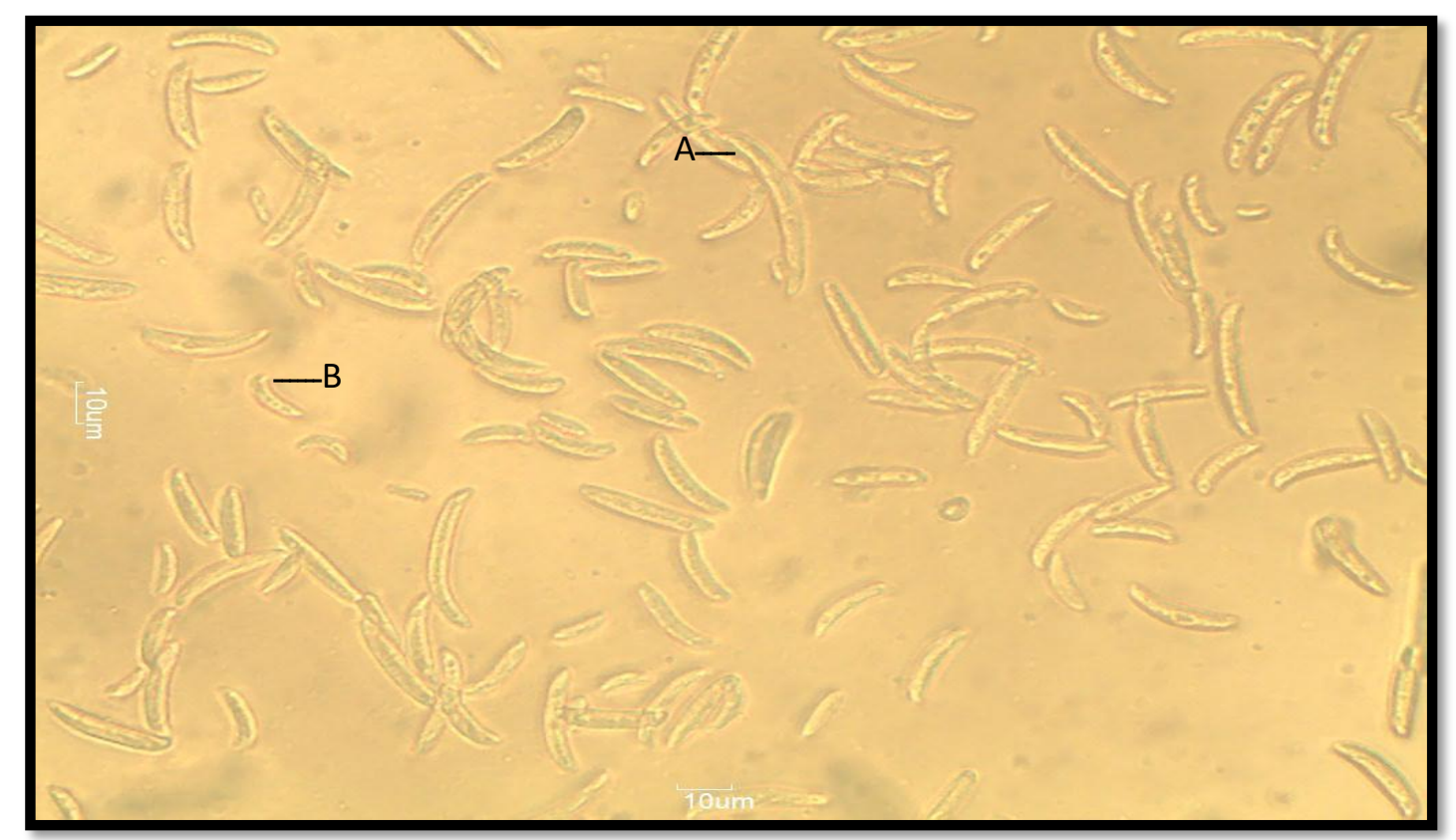

الثكل (3) كونيدات الفطر الكغيرة (microconidia) الكبيرة -A F. solani) بقوة تكبير 40X.

M.phaseolina Tassi Goid تثخيص الفطر

ظهرت على الوسط الزرعي PDA مستعمرات سريعة, النمو وكان الغزل الفطري شفاف في البداية مائل الى اللون الأبيض ثم تحول

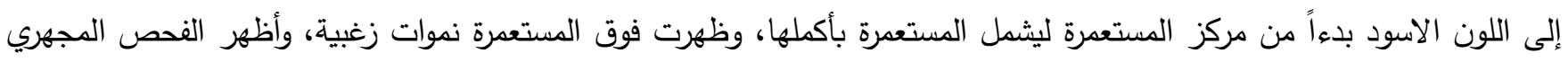

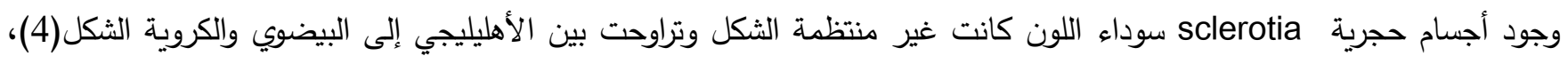

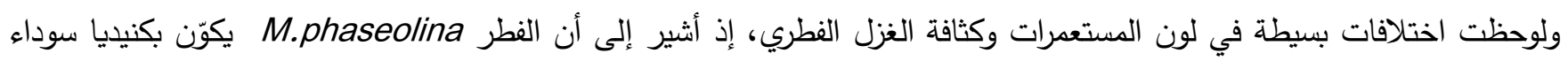

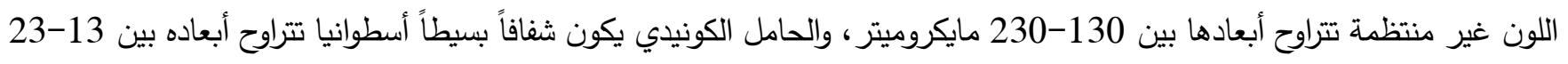
× 3-6 مايكروميتر ، والكونيديا تكون شفافة أسطوانية الثكل أبعادها 14-35 × 6 × تكون سوداء اللون تتراوح أقطارها بين 60-120 مايكروميتر والخيط الفطري 2.5- 7.5 مايكروميتر (36 و 37 و و 38 و و39) 


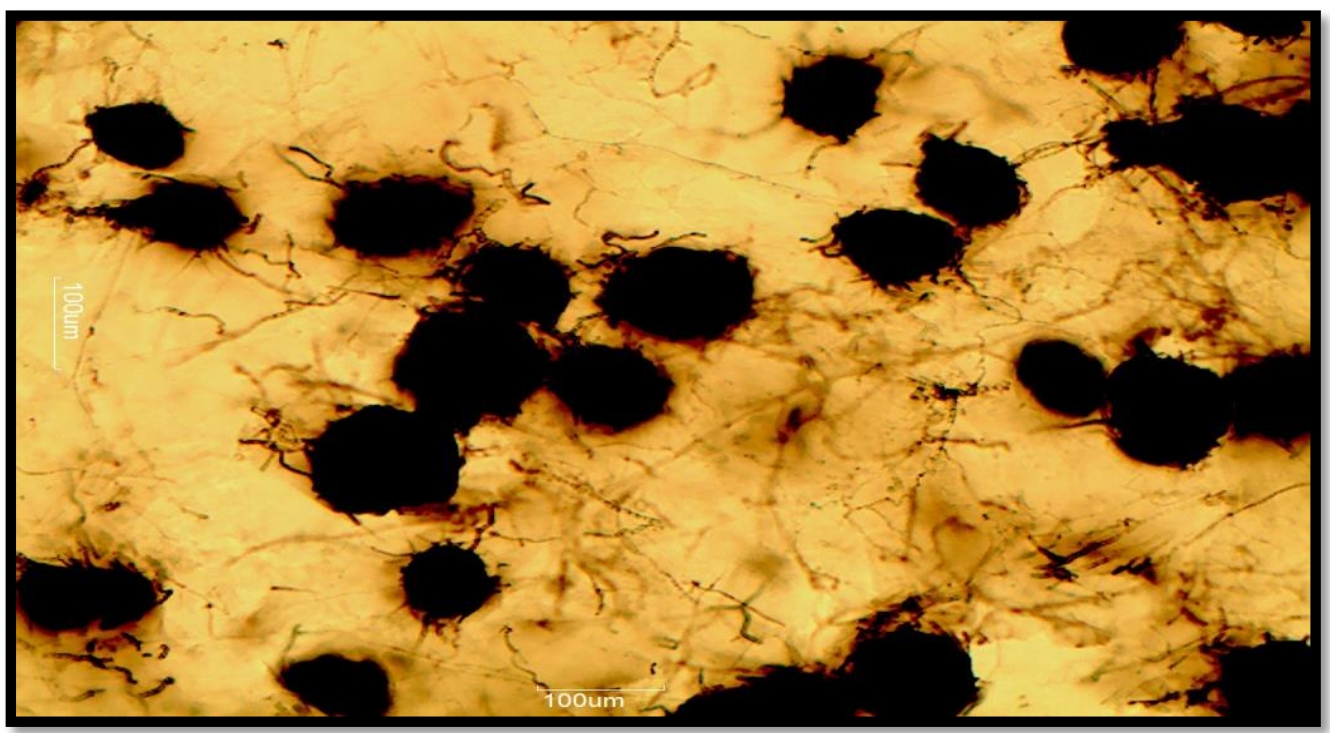

الثكل (4) الاجسام الحجرية للفطر.M. phaseolina تحت القوة 10X.

Rhizoctonia solani Khun تثخيص الفطر

ظهرت مستعمرة الفطر R. solani النامية على الوسط الغذائي PDA بعر ثمانية ايام في درجة حرارة 25 25 سليزية بلون

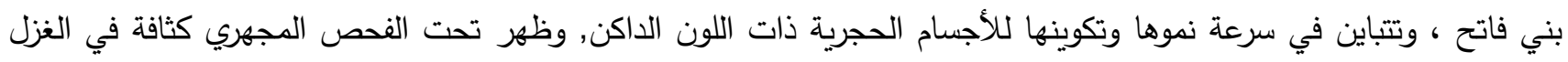

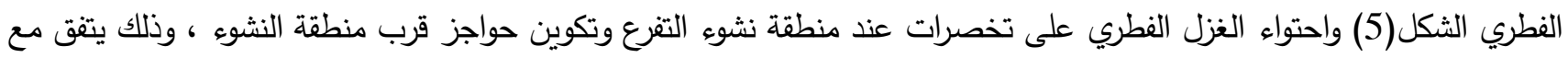

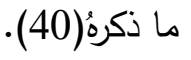

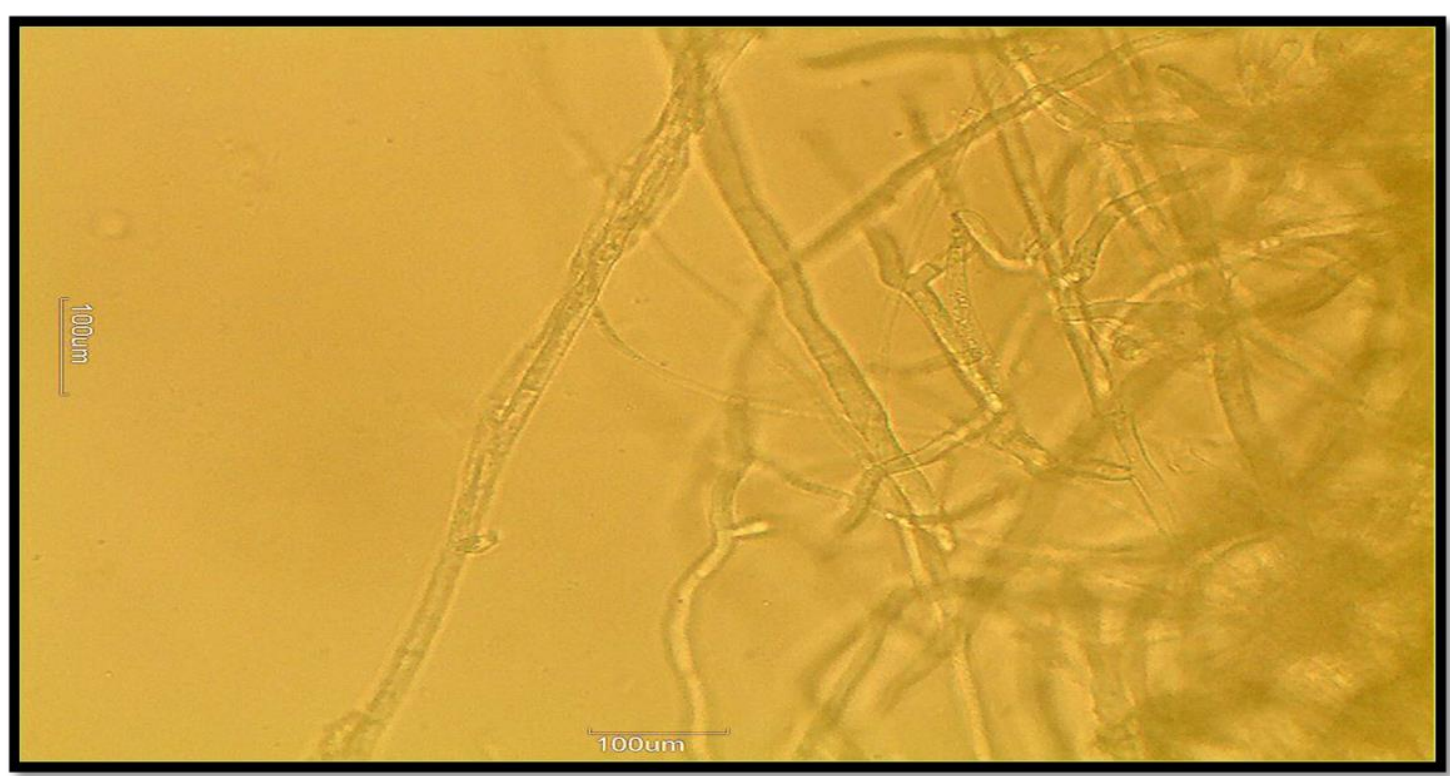

الثكل (5) الغزل الفطري للفطر . R. solani. تحت القوة 40X. 


\section{اختبار القدرة الامرضية للفطريات المسببة تعفن جذور شتلات الصنوبر المعاة صناعياً.}

M. اجري اختبار القدرة الامراضية للفطريات المعزولة من الصنوبر البروتي على شتلات سليمة والملقحة بالفطريات F. solani و R. solani phaseolina M. phaseolina الاخرى حيث بلغت نسبة الإصابة لشتلات الصنوبر البروتي وبتأثير العدوى الصناعية الى 81.25\% تلاه الفطر الذي بلغت نسبة اصابته لشتلات الصنوبر وبتأثير العدوى الصناعية الى 68.75\%. في حين سجل الفطر R. solani ادنى نسبة اصابة لشتلات صنوبر البروتي وبتأثير العدوى الصناعية بلغت 56.25\%.

نستنتج مما سبق تميز الفطر F. solani بالإمراضية العالية للصنوبر البروتي مقارنةً مع بقية الفطريات, رإذ أن هذه الفطريات ذات قدرة

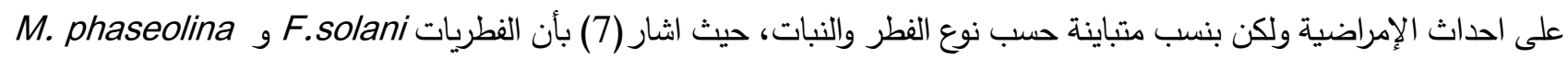
ذا قدرة امراضية عالية بلغت 68 و86\% على التوالي لشتلات اشجار الصنوبر والسرو والكازورينا المسببة مرض تعفن الجذور ، وقد

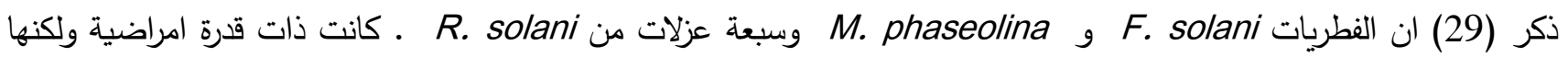
متباينة على شتلات أشجار الغابات المسببة موت البادرات وتعفن جذور شتلات الصنوبر البروتي والثويا والسرو العمودي والسرو

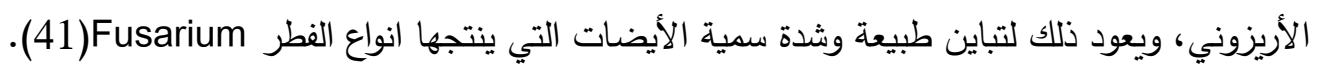

اما الفطر Folani فيعد من الفطريات ذات الإمراضية الواسعة على بادرات الغابات وبخاصةً على الصنوبريات (42). فضلا

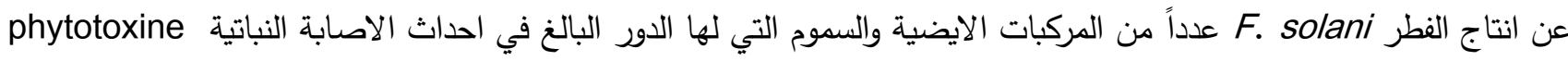

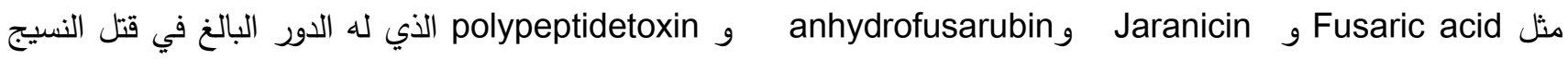
النباتي ومن ثم غزوه من خلال تطفله غير الحيوي Necrotrophic (43) .وكنلك الفطر M. phaseolina فيعد واحداً من الفطريات المدمرة لمشاتل الصنوبر في الولايات المتحدة واستراليا والهند (44). وبين(45). قد يعود السبب في تباين القدرة الامر اضية الى انتاج

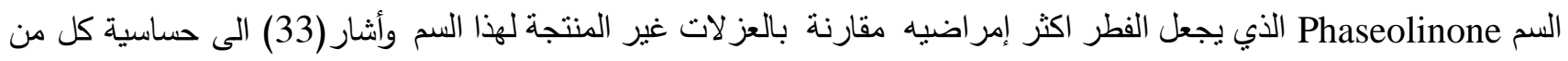

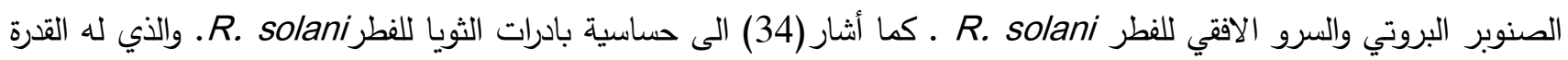
على إفراز الإنزيمات المحللة كأنزيم السليليز Celluase والبكتنيز Pectinase وغيرها من الإنزيمات المهمة ذات التأثير السام مثل سم Phenyl acetic acid (PAA) او مشتقاته الهيدروكسيلية (46).

اختبار تأثير القدرة الامراضية للفطريات في صفات النمو لثتلات الصنوبر البروتي.

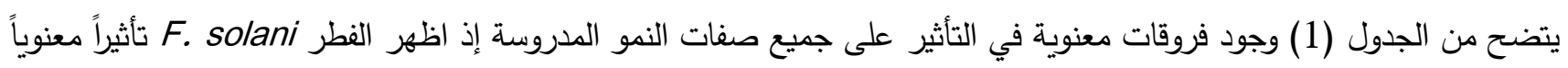

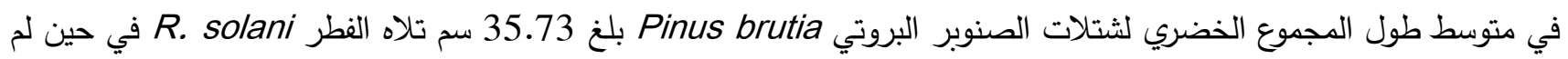

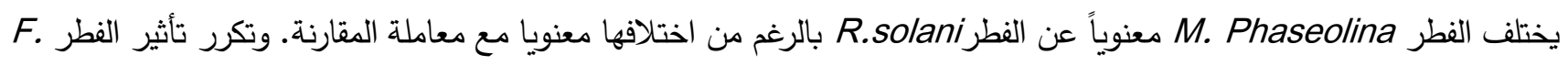
solani. كأدنى متوسط تأثير لصفة الوزن الرطب للساق حيث بلغت كذلك الحال مع صفتي الوزن الجاف وطول المجموع الجذري إذ تميز الفطر F. solani بتأثيره معنوياً بأظهار اقصى تأثير للصفتين

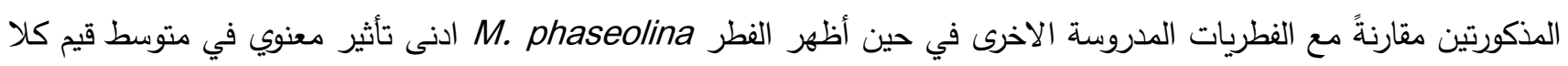

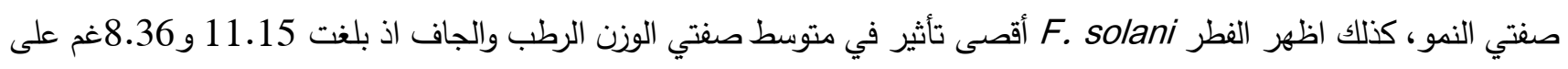


التوالي، في حين أظهر الفطرiR. solani أقل فرق معنوي بالتأثير في متوسط الصفتين إذ بلغتا 14.47 و12.30 غم بالرغم من اختلافهما معنوياً مع معاملة المقارنة. مما سبق يتضح بأن الفطريات المختبرة قد أثرت في معظم صفات النمو من طول المجموع الخضري والجذري والوزن الرطب والجاف

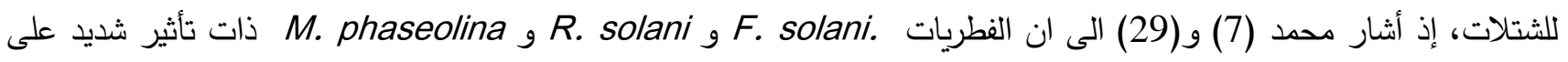
صفات النمو من طول الساق وطول الجذر والوزن الرطب والجاف لعدة شتلات من اشجار الغابات منها الصنوبر البروتي، وقد

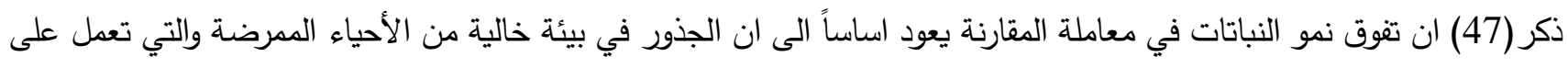

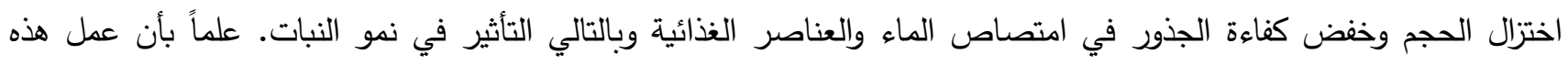

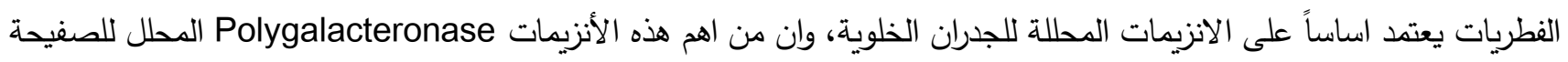

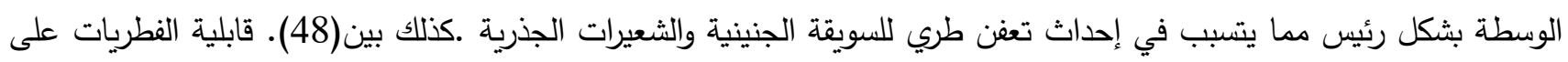

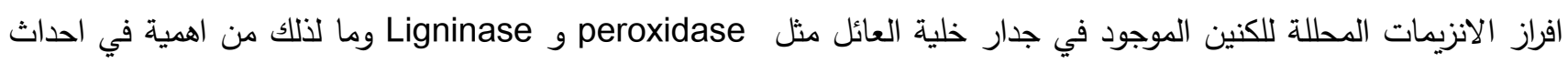

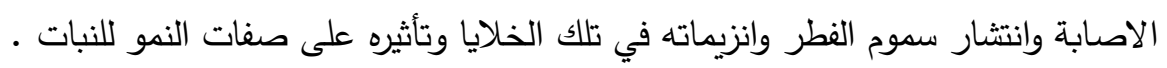

الجدول (1) تأثير العدوى الصناعية لفطريات تعفن الجذور في \% للإصابة وبعض صفات النمو الطبيعية لشتلات الصنوبر

\begin{tabular}{|c|c|c|c|c|c|c|c|}
\hline وزن جاف & وزن رطب & طول المجموع & وزل & وزن رطب & طول المجموع & \% للإصـابة & الفطريات \\
\hline 13.58 & 18 & 42.56 & 23.27 & 40.18 & 44.50 & 0 & \\
\hline A & A & A & A & A & $A$ & D & مقارنة بدون فطر \\
\hline 11.27 & 13.78 & 30.81 & 16.93 & 25.48 & 37.57 & 68.75 & \\
\hline C & B & $C D$ & B & $\mathrm{BC}$ & B & BC & M.phaseolina \\
\hline $12.30 \quad \mathrm{~B}$ & $\begin{array}{c}14.47 \\
\text { B }\end{array}$ & $\begin{array}{l}32 \\
\mathrm{BC}\end{array}$ & $\begin{array}{c}15.86 \\
\text { B }\end{array}$ & $\begin{array}{c}22.34 \\
\text { C }\end{array}$ & $\begin{array}{c}36.87 \\
\text { BC }\end{array}$ & $\begin{array}{c}56.25 \\
\text { C }\end{array}$ & R.solani \\
\hline 8.36 & 11.15 & 23.94 & 12.55 & 15.24 & 35.73 & 81.25 & \\
\hline $\mathrm{DE}$ & $C-D$ & EF & C & D & C & $A$ & F. solani \\
\hline
\end{tabular}

الأرقام التي تحمل أحرفاً متشابهة في العمود الواحد تدل على عدم وجود فروقات معنوية بينها على مستوى إحتمال(0.05) .

تأثير المستخلص الكحولي والمائي في نسب تثبيط نمو الفطريات

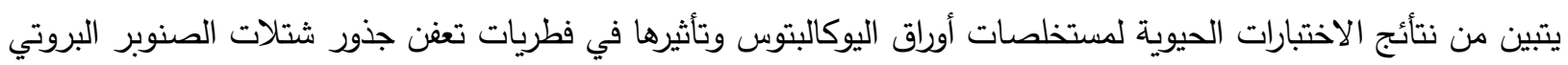
وكما مبين في الجدول (2) صفة تثبيط النمو ظهر الفطر R. solani تأثر بتفوق التركيز الاول من المستخلص المائي لأوراق اليوكالبتوس في تثبيط نمو الفطر وارتفع التثبيط لييلغ 100\% بالتراكيز الثلاثة الاخيرة باستثناء مستخلص الكحولي الذي تفوق في في

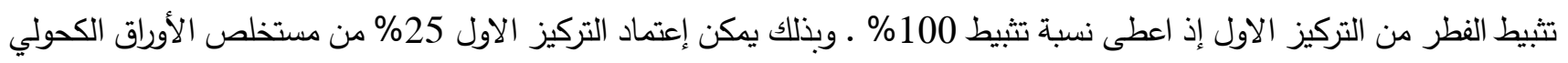




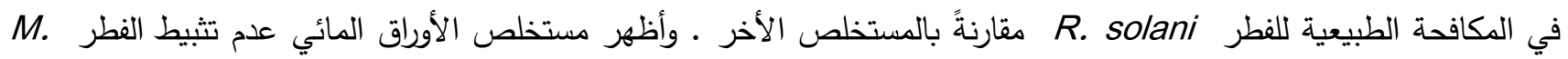
نهائياً حتى مع زيادة التركيز من 25 phaseolina

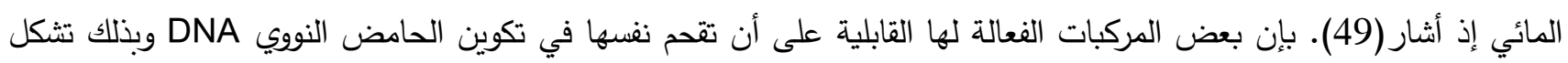

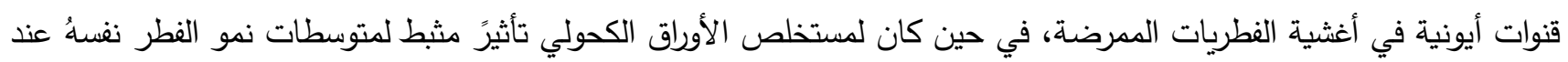

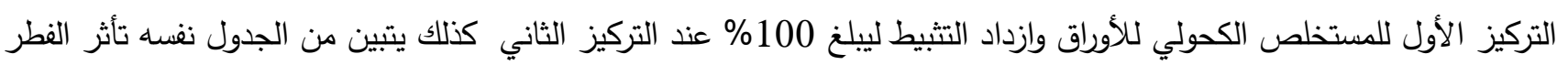
F. solani

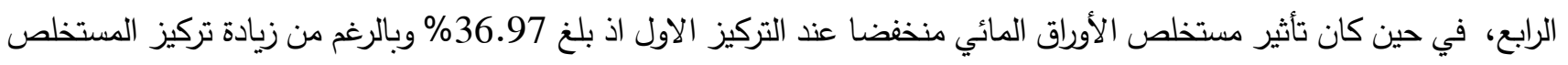

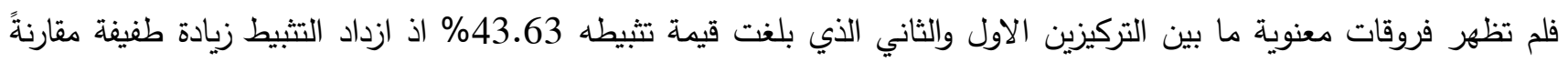

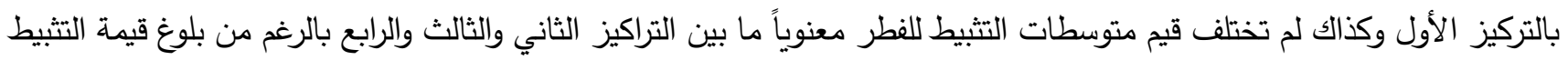

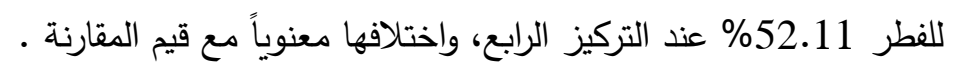

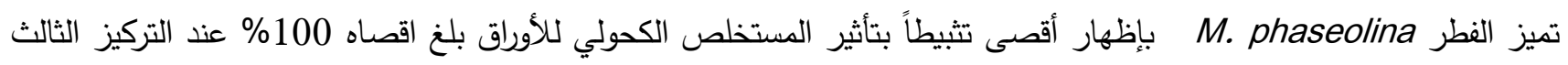

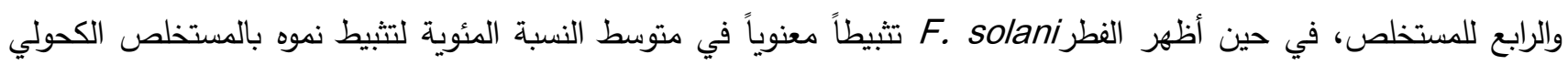

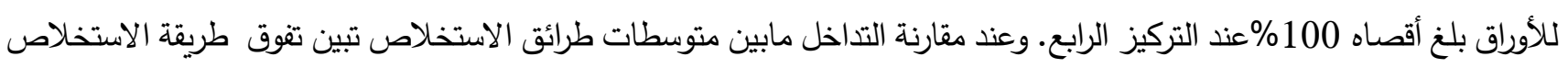
الكحولي للأوراق في تثبيط جميع الفطريات المختبرة ومن ملاحظة متوسطات تداخل الاستخلاص مع الفطريات أن مستخلص الأوراق

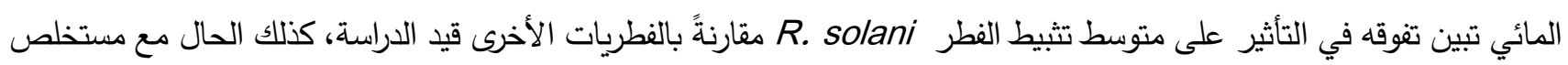

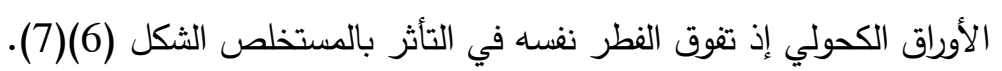
الجدول(2) تاثير تراكيز مختلفة من مستخلصي أولق اليوكالبتوس في نسب تثبيط نمو الفطريات

\begin{tabular}{|c|c|c|c|c|c|c|c|c|}
\hline \multirow{3}{*}{ متوسطات } & \multirow{3}{*}{ متوسطات } & \multirow{2}{*}{\multicolumn{5}{|c|}{ النسبة المئوية لتنبيط النمو (ملم) }} & \multirow{3}{*}{ نوع الفطر } & \multirow{3}{*}{ الدسنخلص } \\
\hline & & & & & & & & \\
\hline & & $100 \%$ & $75 \%$ & $50 \%$ & $25 \%$ & $0 \%$ & & \\
\hline 76.42 & \multirow{6}{*}{$\begin{array}{c}39.54 \\
\text { B }\end{array}$} & 100 & 100 & 100 & 86.06 & 0 & R.solani & \multirow{6}{*}{ الأورائي } \\
\hline A & & A & A & A & BC & $\mathrm{N}$ & & \\
\hline 50.67 & & 52.11 & 47.30 & 43.63 & 36.97 & 0 & F. solani & \\
\hline B & & I-K & $\mathrm{JK}$ & $\mathrm{KL}$ & LM & $\mathrm{N}$ & & \\
\hline 35.88 & & 0 & 0 & 0 & 0 & 0 & M.phaseolina & \\
\hline \multirow[t]{9}{*}{ C } & & $\mathrm{N}$ & $\mathrm{N}$ & $\mathrm{N}$ & $\mathrm{N}$ & $\mathrm{N}$ & & \\
\hline & \multirow{8}{*}{$\begin{array}{c}70.91 \\
\text { A }\end{array}$} & 100 & 100 & 100 & 78.18 & 0 & R.solani & \multirow{6}{*}{ الكستخلص } \\
\hline & & A & A & A & $B-E$ & $N$ & & \\
\hline & & 100 & 83.03 & 79.99 & 63.63 & 0 & F. solani & \\
\hline & & A & $B-D$ & B-E & GH & $N$ & & \\
\hline & & 100 & 100 & 85.45 & 73.33 & 0 & M.phaseolina & \\
\hline & & A & A & $\mathrm{BC}$ & EF & $\mathrm{N}$ & & \\
\hline & & 75.35 & 71.72 & 68.17 & 56.36 & 0 & \multirow{2}{*}{\multicolumn{2}{|c|}{ متوسطات تأثير التراكيز }} \\
\hline & & A & B & C & D & E & & \\
\hline
\end{tabular}

الارقام التي تحمل أحرفاً متشابهة في العمود تدل على عدم وجود فروقات معنوية بينها على مستوى احتمال(0.05) 
Journal of Education and Science (ISSN 1812-125X), Vol: 29, No: 1, 2020 (75-92)

F.solani=C M.phaseolina=B R.solani=A شكل (6) تأثير مستخلص الأورلق المائي على نمو الفطريات

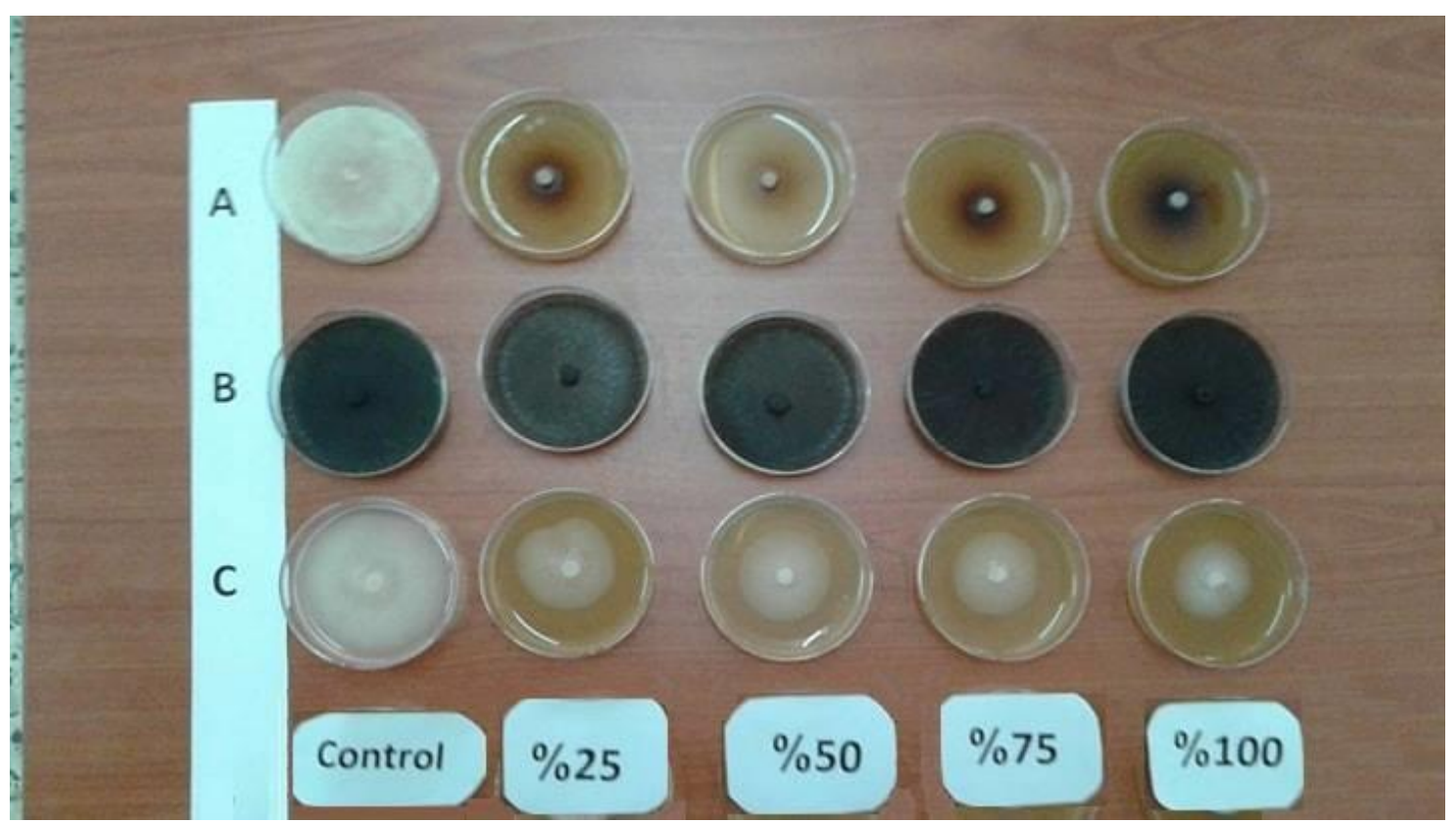

F.solani=C M.phaseolina=B R.solani=A شكل (7) تأثير مستخلص الأولق الكحولي على نمو الفطريات

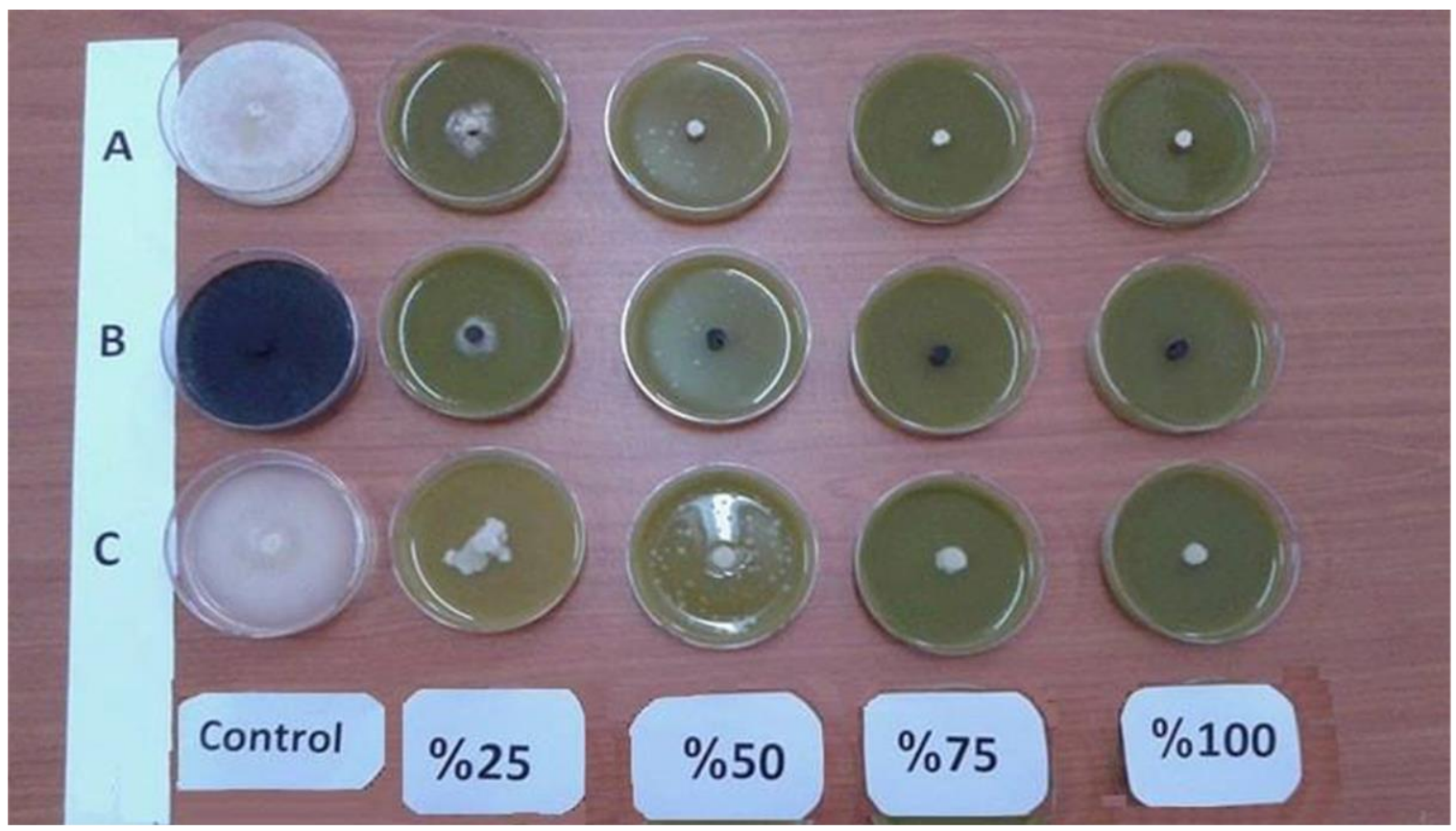


إن الفعل الفسلجي للمستخلصات المائية النباتية في التأثير على بعض الفطريات قد يعود الى طبيعة محتواها من المواد الفعالة التي لها القدرة في تثبيط نمو الفطر ، إذ فسر (50) تأثير

المستخلصات المثبطة للفطريات قد يكون ناجماً عن تأثيرها في منع إنبات الأبواغ أو تأثيرها في تغير نفاذية اغثية الخلية أو تأثيرها

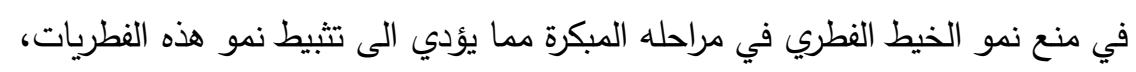

ان تفوق المستخلص الكحولي على المستخلص المائي في زيادة نسبة التثبيط بشكل عام قد يعود الى قابلية ذوبان بعض المركبات

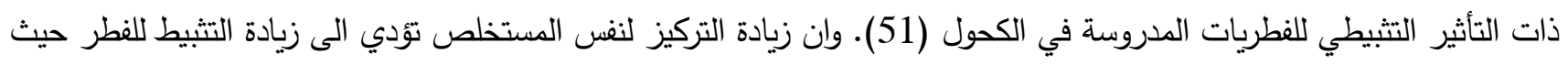

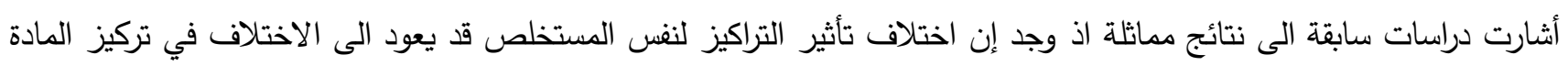

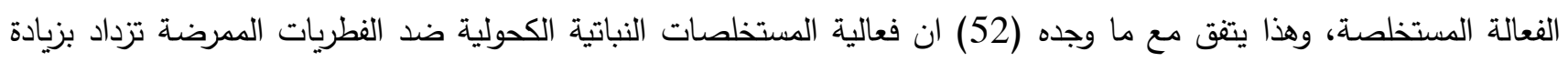
التركيز، يعود السبب في ذلك الى تأثير المواد الفعالة في الخلية الفطرية وتداخلها مع التراكيب الخلوية والعمليات الأيضية إذ تؤدي فئي الى حدوث تغيرات في التراكيب الدقيقة للخلية الفطرية والخيط الفطري وهذه التغيرات ترتبط بفقدان قوة الجدار الخلوي المسؤول عن فئ قوة وتكامل شكل الخلية ولان الجدار الخلوي يعد أحد المواقع الهدف لعمل المواد الفعالة وتسبب التغيرات من التداخل المباشر ما بين المواد الفعالة ومكونات الجدار أومن عمليات بناء الجدار (53). كذلك تتفق هذه النتائج مع ما وجدهُ(54). حول احتواء مستخلصات التهات

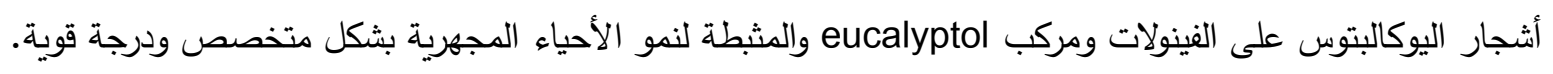


1-نواجد مرض تعفن الجذور في مشاتل الموصل الخاصة ومحطة بستنة نينوى خلال أشهر السنة محدثاً تعفناً في جذور شتلات

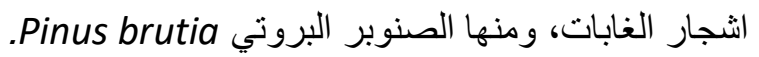

2- ظهور الفطريات F.solani و M.phaseolina و مر افقة لجذور شتلات الصنوبر البروتي المصابة وذلك بعد عزل الفطريات منها خلال أشهر السنة. 3- تفوق الفطر F.solani بأعلى نسبة عزل.

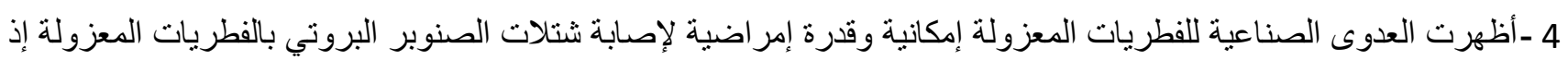

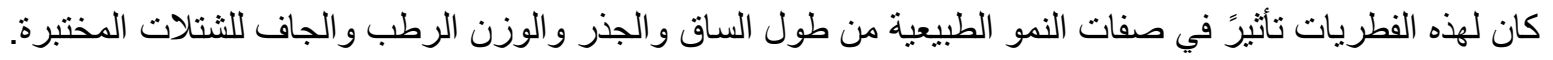
5- تباين القدرة الإمر اضية للفطريات إذ كان الفطر F.solani الأكثر تأثير اً على صفات النمو الطبيعية لشتلات الصنوبر البروتي 6- تفوق المستخلص الكحولي للأوراق على المستخلص المائي في تثبيط نمو الفطريات F.solani و و M.phaseolina و وعند جميع التراكيز المستخدمة.

7- تميز المستخلص المائي للأوراق في تثبيطه نمو الغزل الفطري للفطر R.solani عند جميع التراكيز المستعملة ويعد هذا منحى

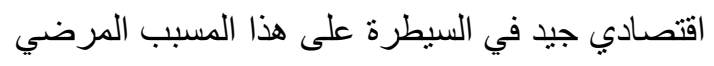

References المصادر

1-Palta, M.M., Richardson A.E., Sharitz R.R. Institute of Ecology, The University of Georgia, Athena. (2003).

2- Kiss, D.Á., Kiss D.G, Hufnagel L.. Applied ecology and environmental research 6(2): 111-134. (2008).

3-Malmsheimer, W.R., Bowyer L.J , Fried S.J., Gee E., Izlar L.R., Miner, A.I., Munn A.R., Oneil E., and Stewart C.W. A Society of American Foresters Task Force Report. Journal of Forestry. 109, (7S): 7-51. . (2011).

4- Nahal, I. " Dendrology", Faculty of Agriculture, Aleppo University, Syria. (2003).

5- Dawood, M. D. Classification of forest trees. MosulUniversity, Ministry of Higher Education and Scientific Research, Republic of Iraq. (1979).

6- Abdullah, Y. S. "Fundamentals of forest development". Mosul University, Ministry of Higher Education and Scientific Research, Republic of Iraq. (1988).

7- Muhammad, A. N. Master Thesis, College of Agriculture and Forestry, Mosul University, Iraq. (1987).

8- Sunderrao R.R; Simon S., and Lai A. Dianthe6(5)1558 1559.(2017).

9- Al-Kaif, M.A.O. Master Thesis, Middle Euphrates Technical University, College of Technology, Musayyib, Iraq(2015). 
10- Thenmozhi, K.; M. Saradha; M. Manian, and S. Paulsamy, Invitro antimicrobiall potential of root extracts of medicinal plant species(2013).

11-Johnson M.; MacDougall C.and Ostrosky-Zeichner L. "

Combination antifungal therapy. Antimicrobial Agent and chemotherapy". 48:693-15(2004).

12- Bajwa , R. and S. Iftikhar .. Myco path. 3.Pp: 13-16. (2005).

13-Dossari, Nasser Hamid. Journal of Karbala University. Volume (5), Issue (4). (2007).

14-Mulla A., Faten N. H., Ghaidaa S. and Ramadan N. A. Tikrit Journal of Pure Sciences. Vol. 15, No. 2, p. 221-227. (2010).

15-Mubark E.E.; Ali L.Z. ; Ahmed I.FA.; Ali AB..Int J Agr Biol. 17(2):320-326.( 2015).

16- Shayoub M.H.; Dawoud A.D.H; Abdelmageed M.AM.; Ehassan A.M. " Phytochemical analysis of leaves extract of Eucalyptus camaldulensis Dehnh.2(1). (2015).

17-Rikar , A.J. and Rikar R.S. "Introducation to research on plant diseases" .J.S. Swift Co. Incorporation. Louis and New York. 117 pp. (1936).

18-Parmeter, J.R.;and Whitney H.S. " Taxinomy and nomenclature of the imperfect stage In:Rhizoctonia solani Biology and Pathology" .(ed) J.R.Parmeter.University of California Barkely. LosAmgeless. 7-19 pp. (1970).

19- Barnett, H.L and Hunder B.B. " bill striated Genera of imperfect fungi" .22pp. (1972).

20- Booth ,C. "Fusarium Labortory guide to the identification of the major species" commonwealth Mycological Institute.Key,surrey, England .58pp. (1977).

21-Leslie , J.F. and Summerell B.A. " the Fusarium Laboratory Manual photographs by Suzanne Bullock".388. pp .(2006) .

22-Taha, K.H; A1-Mallah N.M. and Al-Tayy A.K. Agris. Sci.(zanco) , 4: 24 219. ( 1986).

23- Hearther, W.A.; Pratt B.H.and Shin T.Y. Aust. J. Bot. 25:385-393. (1977).

24-Salman, Munib Taher. PhD thesis, College of Agriculture and Forestry, University of Mosul, Iraq. (2006).

25-Browning, B.L. "Method of wood chemistry. Vol.1 Institute of paper chemistry" . Appleton, Wisconsin, Inter Science Publishers . A Division of John Whley and son(1967).

26- Harborne, J.B. " Phytochemical Methods: Aguide toModern Technique of Plant Analysis". 1st ed., Cox and Wyman London, p 52-73. (1973).

27-Khanzada, Sh. A., Iqbal S. M. and Akram A. Mycopath., 4: 51-53. (2006).

28-Narrator, K. M. and Abdul Aziz .M. K A. Design and analysis of agricultural experiments. Mosul University, Ministry of Precious Education and Scientific Research, Iraq. (2000).

29-Ali, R. M S., Master Thesis College of Agriculture, Sulaymaniyah University, Iraq (2007).

30-Ahanger, M.A.; G.H.,Dar; Z.A.,Baht and N.R.,Sofi ". Plant pathology Jourmal 10(1):4245(2011). 
31 -Booth, C. "The genus Fusarium ".Common. Mycol. Inst. Kew, Surrey. 237pp(1971).

32-Brasileiro, B. T. R. V. , Coimbra M. R. M. , Jr M. A. M. and Oliveira N. T. Brazillian Jornal of Microbiology. 35 : 205-210. (2004).

33- Younis, M. M. Master Thesis, College of Agriculture and Forestry, University of Mosul, Iraq (1981).

34- Taha, Khaled Hassan. Journal of the cultivation of Rafid 26- 185-177: (1994).

35- Toussoun, T.A., and P.E, Nelson "Apictorial Guide to the Identification of Fusarium species". 2 nd ed. Pennsylvania state University press, University park. 43p. ( 1976).

36-Ashby, S. F. Butl. Trans. Br. Mycol. Soc. Butl. Trans. Br. Mycol. Soc. 12:141-147. (1927).

37- Watanable, T . Phytopathol. Soc. Jpn. 38:106-110. (1972).

38-Sutton, B. C . " The Coelomycetes. Commonw". Mycol. Inst., Kew, 696 pp. (1980).

39-Fernandez, R. B. ; A. De Santiago ; S. H. Delgado and N. M. Perez"Characterization of Mexican and non-Mexican isolates of Macrophomina phaseolina based on morphological characteristics", Pathogenicity on bean seeds and endoglucanase gene . Plant Pathology $88: 1$. (2006) .

40- Carling, D. E.; R. E. Baird; R. D. Gitaitis; K. A. Brainard and S. Kuninaga. " Characterization of AG-13, a newly Reported anastomosis group of Rhizoctonia solani. Phytopathology 92:893-899. (2002).

41- Fernandez,M.R. and Chen Y.. Plant Disease 89:164-169. (2005).

42- Wenner, N. and Merrill W. " New conifer host for fusarium root rot in pensylvania". Plant Dis. 68:538. (1984).

43- Strange, N.R. " Plant Diseases Control. Towards environmentally acceptable methods published by Chapman and Hall 2-6 Boundary Row", London SEI8 HN. 355pp. (1993).

44- Jamaluddin, V, and Soni X.X"Studies on charcoal root rot of Pinus cribea". Indian Forester. Septomber.P. 618-621. (1982).

45- Suchandra ,S.;Mishra S. K.; Kazia I. and Siddiqui .. J. Biosci. 25 (1) : 73 - 80. (2000).

46- Ogoshi, A. C. F. snech, B., Hare, H. J., Neak, E. F. and Gijse, J. " Introduction. The genus Rhizoctonia 1 - 9pp. Rhizoctonia species : Taxanomy, Mollecular Biology, Ecology, Pathology and disease control", Kluwer Aceademic pulishers printed in Netherlands 585pp. (1996).

47-Agrious, G. N. " Plant Pathology". (4 ${ }^{\text {th }}$.ed.). Academic Press, New York. 606 pp. (1997).

48- Lozovaya , V.V. ; Lygin A.V. ;. Zernova O.V , Li S. , Widholm J. M. and Hartman G.L. plant Dis . 9: 77-82 . (2006).

49- Khazraji, A J. A H., Iman A. K., Adel S. Salman E. S. H. and Kalbawi A M. N. Journal of Biotechnology Research Center. Volume 9 Issue 1. .14-9 (2015). 
50- Wen-Bao, C.; Yuh-Felling H.; Shung C.J. and Sheno C.C. " Isolation, purification and characterization of killer protein from Schwanniomyces occidentalis" Appl. Environ. Microbiol. 66: 5348-5352. (2000).

51-Lawrence, Ch.; Mitchell Th.; Craven K.; Cho Y.; Cramer R. and Kim K. ". Plant Pathol. 24 (2): 101-111. (2008)

52- Paran,B.; Sharma R.K.; Singh R.S; Ghosh A.C. and Baruah P. Journal of Essential oil Research.8:411-412. (1996).

53-Otang, W.M. ; Grierson D.S. and Nadip R.N. INT.J. Mol. Sci.Vol.(12) : 9226-9235. (2011).

54-Rai , M.K. ; Qureshi, and Pandy , A. K. In Vitro susceptibility of opportunistic . Fusarium spp. to essential oils. Mycoses 42 : 97 - 101. (1999). 